\title{
Archaeology for the Humanities?
}

\author{
Poul Holm
}

Felix Riede makes a broad claim in the title - that knowing about deep pasts will help knowing about deep futures. In fact, he does not talk very much about futures but, if I am right, the logic is that a millennial perspective on human existence will help us think beyond what he calls the 'shallow Anthropocene' (i.e. the recent past and perhaps the immediately foreseeable future). In one sense, this is certainly right. Understanding the history of a phenomenon throws a perspective on the present. In this line of reasoning, Riede follows the same logic as the History Manifesto by Jo Guldi and David Armitage who argue that '[i]n the context of a deep past, conversations about a deep future may once again become possible' (Guldi \& Armitage 20I4:35). Understanding time - through the lens of historical sciences such as geology, archaeology and history - provides us with a sobering perspective on the precarious nature of that which may seem stable and durable.

There are, however, limitations to the logic. The human future is fundamentally unknowable because there is no way of predicting human innovation, action and reaction, not to speak of the problems of modelling hypercomplex systems. Predictions are therefore fraught with problems and the best we can do is to establish scenarios. Scenarios are limited by the power of our imagination. The past can fuel our imagination but will not repeat itself. History may tell us when and how we got locked into a certain path, and scenarios may help identify how to unlock our path dependency. In a

Department of History, Trinity College Dublin 
practical sense, the historical sciences help identify what we have lost and changed (biotopes, species diversity, landscapes), and accordingly inform managers of what may be regenerated and what is forever lost. In these ways, historical insight is crucial for short- to medium-term decision models on relatively stable parameters. History may not, however, help us much when we imagine 'deep futures' of a complex and innovating system. Philosopher Karl Popper famously warned against the Poverty of Historicism in a polemic against future predictions by Plato, Marx and others. Let's take heed. Archaeology is as unable as any other discipline to predict the human future in a hundred years' time. From deep pasts to deep futures is a great phrase but it may cloud our vision.

Apart from this quibble about the title, I agree that archaeology has an important role to play for our immediate future. Riede argues convincingly that archaeology needs to develop a pro-environmental dialogue through museums and public media and to be aware of the discipline's often problematic role as a builder of identity. Riede is right that archaeologists need to raise the alarm that archives in the ground are rapidly being lost because of environmental and climate change. In order to play that public role, it is important that archaeologists team up with other interested parties, including colleagues in the humanities.

Public service is an important reason to establish nodes such as centres for environmental humanities. Academics are notoriously poor at speaking up in unison on matters of joint concern, and we are even worse at organising ourselves to fit the purpose. Centres for environmental humanities may help us join up across disciplinary boundaries and address a wider agenda. As an example of how this may be done, I point to the global Humanities for the Environment observatories (Humanities for the Environment 2019), which include a wide range of disciplines from literary scholars to archaeologists. One important lesson from this experience is that our colleagues in the natural sciences tend to applaud us coming together as a humanities club. Far too often natural scientists only know one or two colleagues in the humanities by sheer coincidence. Identifiable centres of environmental humanities ease collaboration across faculty divides as colleagues may rely on centres to help them identify relevant partners.

Riede confesses to being a reluctant rainbow warrior at best but thinks that archaeology stands to gain a renewed and redefined relevance by casting itself as palaeo-environmental humanities. Riede's argument is strong and raises the question of whether science - including the humanities - can and should have a political agenda. In this concern, the humanities - including archaeology - have so far lived a more sheltered life than the earth and climate sciences. But clearly, ethical and advocacy questions are becoming increasingly important to how we behave as scholars. There is much to be 
learnt and humanities centres may help improve practices of translational humanities -i.e. engaging with and learning from public engagement.

Apart from an advocacy role for archaeology, Riede argues that there is also an academic benefit to thinking of archaeology as a 'palaeo' variant of the environmental humanities. This part of the argument is less clear to me. Riede believes that other disciplines may benefit from the fact that archaeology brings a long-term perspective which is lacking in what he calls 'shallow-time disciplines' such as literature studies and anthropology. This needs qualification beyond Riede's mention of a shared time-window. Major humanities disciplines such as history, classics, art history, philosophy, religious studies, and linguistics operate with a window on the past of the last four or five thousand years in China as well as the Near East, and two thousand years in many other regions. In this, they share a time horizon with the majority of archaeologists. Of course, Neolithic archaeology reaches into times that are closed to most other humanities disciplines, and the Pleistocene world is a powerful contrast to the depleted natural habitats of today. But time-depth is not the unique selling point of archaeology.

Rather, I would argue that archaeology is a contingent assembly of methodologies to wrestle evidence of the past out of material evidence. As a historian myself, I read archaeological papers because they provide unique insights based on inquiry and methods that are beyond my reach. I am interested in archaeology primarily for what it tells me about a problem that concerns me - be it by contemporary or comparative evidence. To me, what makes archaeology a strong component of the historical disciplines is its methodological rigour and technical expertise rather than its longterm perspective.

This observation brings me to ask Riede what archaeologists may learn from working with other humanities disciplines? The paper has much on what archaeologists have to offer, not so much on what they may take away. What is the advantage to archaeology of increasing collaboration with other humanities disciplines? Archaeology is, of course, blessed with lots of collaborative experience with many disciplines, especially in the natural sciences, but less so with humanities disciplines. I have come across archaeologists who have deliberately refrained from learning from historical studies not to mention other humanities approaches - and indeed I have met historians who remain deeply sceptical of archaeology. I would like to know what Riede believes archaeology may learn from the humanities. In particular, I would like him to speak to the large community of environmental historians - perhaps the group of environmental humanities closest to archaeology and yet our paths seldom cross.

Riede claims that environmental humanities have generally risen out of postmodern theoretical approaches which are largely alien to archaeology 
- and leaves it there. I would have welcomed a more head-on discussion. I think Riede gets the historiography wrong because he ignores the one half of environmental humanities centres which are actually born out of environmental history initiatives which were never postmodernist. There is definitely a strand of postmodernism still alive in the humanities though it is much reduced since the heyday of twenty or thirty years ago. I would go so far as to say that the rise of ecocritical approaches in literature may take some of the credit for this demise - it is hard to play word games with disasters - but there is still a way to go, and archaeologists have a vital role to play. This role, as I see it, is not so much to harp on long-term perspectives but to sharpen debates in the humanities about our methodological and analytical skills.

To conclude, I share Riede's ambition to develop the environmental humanities as a platform for curiosity-driven research into how humans have shaped and are transforming our planet. The human and natural past should be the basis for a fruitful dialogue across the humanities and natural sciences, and when it happens it is wonderful. Unfortunately, it happens too infrequently to be the norm. Surely, multidisciplinary collaboration must be the rallying call for the environmental humanities, and archaeology to me is a born member of that club.

\section{References}

Guldi, J. \& Armitage, D. 20I4. History Manifesto. Cambridge: Cambridge University Press.

Humanities for the Environment. 20I9. Welcome to Humanities for the Environment: Observatories of Humanities Researchers https://hfe-observatories.org [Accessed I5 January 20I9].

Popper, K. 1957. Poverty of Historicism. London: Routledge. 